BMJ Open Sport \& Exercise Medicine

\title{
Impact of smoking on patient outcomes after arthroscopic rotator cuff repair
}

\author{
Micah Naimark, Christopher B Robbins, Joel J Gagnier, Germanual Landfair, \\ James Carpenter, Asheesh Bedi, Bruce S Miller
}

To cite: Naimark M, Robbins CB, Gagnier JJ, et al. Impact of smoking on patient outcomes after arthroscopic rotator cuff repair. BMJ Open Sport \& Exercise Medicine 2018;4:e000416. doi:10.1136/ bmjsem-2018-000416

Accepted 3 September 2018

\section{ABSTRACT}

Background Cigarette smoking may adversely affect rotator cuff tear pathogenesis and healing. However, the impact of cigarette smoking on outcomes after arthroscopic rotator cuff repair is relatively unknown. Patients and methods A cohort of 126 patients who underwent arthroscopic rotator cuff repair with minimum 2 years follow-up were retrospectively identified from our institutional database. Patient demographics, comorbidities, and cuff tear index were collected at initial presentation. Outcome measures including American Shoulder and Elbow Surgeons (ASES) score, Western Ontario Rotator Cuff (WORC) score and Visual Analogue Scale (VAS) for pain were collected at each clinical follow-up. Mixed model regression analysis was used to determine the impact of smoking on outcomes, while controlling for tear size and demographics.

Results In our cohort, $14 \%$ were active or recent smokers. At baseline, smokers presented with higher pain, greater comorbidities and worse ASES scores than non-smokers. Smokers also had a non-significant trend towards presenting for surgical repair at a younger age and with larger tear sizes. Both smokers and non-smokers had statistical improvements in outcomes at 2 years following repair. Regression analysis revealed that smokers had a worse improvement in ASES but not WORC or VAS pain scores after surgery.

Conclusion The minimal clinically important difference was achieved for ASES, WORC and VAS pain in both smokers and non-smokers, suggesting both groups substantially benefit from arthroscopic rotator cuff repair. Smokers tend to present with larger tears and worse initial outcome scores, and they have a lower functional improvement in response to surgery.

\section{INTRODUCTION}

\section{(c) Author(s) (or their} employer(s)) 2018. Re-use permitted under CC BY-NC. No commercial re-use. See rights and permissions. Published by BMJ.

Department of Orthopedic Surgery, University of Michigan, Ann Arbor, Michigan, USA

Correspondence to Dr Micah Naimark; micahnaimark@gmail.com
Cigarette smoking adversely affects a variety of musculoskeletal conditions and procedures, including spinal fusion, fracture healing, surgical wound healing, tendon injury and knee ligament reconstruction. ${ }^{1-3}$ More recently, smoking has been suggested to negatively impact rotator cuff tear pathogenesis and healing. ${ }^{45}$ Tobacco smoke contains nicotine, a potent vasoconstrictor that can reduce the blood supply to the already relatively avascular rotator cuff insertion. ${ }^{6} 7$ Furthermore, carbon monoxide in smoke reduces

\section{What are the new findings?}

Both smokers and non-smokers demonstrate good outcomes with arthroscopic rotator cuff repairs.

- Smokers tend to present with larger cuff tears and at younger age.

- Cigarette smoking is an independent predictor of reduced clinical improvement with arthroscopic rotator cuff repairs.

How might it impact on clinical practice in the near future?

While all patients should be counselled on smoking cessation, our results suggest that cigarette smoking is not an absolute contraindication to arthroscopic rotator cuff repair in patients who are unable to quit.

the oxygen tension levels available for cellular metabolism. ${ }^{8}$ The combination of these toxins may lead to the development of attritional rotator cuff tears with a decreased capacity for healing.

The impact of smoking on patient outcomes after arthroscopic rotator cuff repair is not well understood. ${ }^{9}$ Mallon et al first reported that smokers had lower improvements in outcomes following open rotator cuff repairs. ${ }^{10}$ Subsequent studies investigating the clinical impact of smoking on cuff repairs have demonstrated mixed results. ${ }^{11-13}$ The current study reviews our institutional rotator cuff repair database to determine the impact of smoking on rotator cuff repair. We hypothesise that smoking will result in larger rotator cuff tears on presentation and worse outcomes following surgical repair.

\section{METHODS}

We conducted a retrospective cohort study of patients undergoing treatment for full-thickness rotator cuff tears at our institution between 2012 and 2015. The inclusion criteria for the original cohort were age $>18$ years and full thickness rotator cuff tears. Isolated subscapularis tears were excluded. 
Table 1 Patient demographics of smokers and nonsmokers

\begin{tabular}{|c|c|c|c|}
\hline & $\begin{array}{l}\text { Smokers } \\
(n=18)\end{array}$ & $\begin{array}{l}\text { Non-smokers } \\
(n=108)\end{array}$ & $\begin{array}{l}P \\
\text { values }\end{array}$ \\
\hline Age in years, $M(S D)$ & $53.6(11.0)$ & $58.7(8.2)$ & 0.08 \\
\hline \multicolumn{4}{|l|}{ Gender (\%) } \\
\hline Male & $7(38.9)$ & $76(69.1)$ & \multirow[t]{2}{*}{$0.013^{*}$} \\
\hline Female & $11(61.1)$ & $34(30.9)$ & \\
\hline $\begin{array}{l}\text { Body mass index, } \\
\text { M (SD) }\end{array}$ & $31.4(6.8)$ & $29.4(5.8)$ & 0.25 \\
\hline $\begin{array}{l}\text { Cuff tear index, } \\
\text { M (SD) }\end{array}$ & $5.5(4.6)$ & $3.6(3.1)$ & 0.11 \\
\hline \multicolumn{4}{|l|}{ Diabetic (\%) } \\
\hline Yes & $3(16.7)$ & $13(11.8)$ & \multirow[t]{2}{*}{0.56} \\
\hline No & $15(83.3)$ & $88.2(97)$ & \\
\hline \multicolumn{4}{|c|}{ Worker's compensation (\%) } \\
\hline Yes & $3(16.7)$ & $5(4.5)$ & \multirow[t]{2}{*}{0.06} \\
\hline No & 15 (83.3) & $105(95.5)$ & \\
\hline $\mathrm{FCl}$ & $1.8(1.7)$ & $0.91(1.1)$ & $0.04^{*}$ \\
\hline ASES & $42.1(18.2)$ & $52.3(18.3)$ & $0.04^{*}$ \\
\hline VAS Pain & $69.9(22.8)$ & $52.8(18.3)$ & $0.007^{*}$ \\
\hline WORC & $1386.4(434)$ & $1213.2(370)$ & 0.12 \\
\hline
\end{tabular}

*Indicates $\mathrm{p}<0.05$.

ASES, American Shoulder and Elbow Score; $\mathrm{FCl}$, functional comorbidities index; M, mean; VAS, Visual Analogue Pain Score; WORC, Western Ontario Rotator Cuff index.

In our institution, patients were counselled on operative and non-operative management of their rotator cuff tears based on their symptoms, activity level, tear size and treatment goals.

For the purposes of this study, we included only patients who underwent arthroscopic repair with a minimum of 2 years follow-up. Out of 234 patients with full thickness rotator cuff tears treated at our institution in the study period, 136 underwent arthroscopic rotator cuff repairs. Two-year follow-up was available for 126 (92.6\%) patients. Of the 10 patients lost to follow-up, there was one smoker and nine non-smokers. The patients lost to follow-up did not differ significantly in smoking status, demographics or baseline scores compared with the included cohort. Surgery was performed by one of three fellowship trained shoulder surgeons. All repairs were performed arthroscopically, with the repair technique and suture configuration left to the discretion of the treating surgeon.

Demographic information was collected at baseline including age, sex, weight, height, worker's compensation status, diabetes and other comorbidities combined into the Functional Comorbidity Index. ${ }^{14}$ Smoking status and quantity were collected by questionnaire. Patients were considered smokers if they reported smoking within 3 months prior to surgery. Smoking amount was quantified by patient reported average number of cigarettes per day. Cuff tear size was measured on preoperative MRI. Cuff tear index (CTI) was calculated from the preoperative MRI scans by multiplying the tear mediolateral dimension by the anteroposterior dimension to generate the surface area of the tear. ${ }^{15}$

Patient outcomes were collected preoperatively and at 4, 8, 16 and 32 weeks as well as 1 year and 2 years postoperatively. The primary outcome measure was the American Shoulder and Elbow Surgeons (ASES) score, secondary outcomes included the Western Ontario Rotator Cuff (WORC) index scores and Visual Analogue Scale (VAS) for pain. The mean change from baseline to final follow-up was calculated and used for each dependent variable (ASES, WORC and Pain VAS).

Descriptive and inferential statistics were analysed using SPSS V.22.0 (IBM, Armonk, New York, USA). First, we described the demographic, clinical and related characteristics across included patients by using raw counts, measures of central tendency (eg, mean, median or mode) and measures of data dispersion (eg, 95\% CIs, SEs) where appropriate. The Expectation-Maximisation imputation procedure was used to impute missing data for all outcome measures which provides more robust SEs and low risk of bias versus simple mean imputation or list-wise deletion. Comparisons between the smoking and non-smoking groups for each independent variable of interest were carried out with the Student's t-test for continuous variables and the $\chi^{2}$ test for categorical variables. Three models were constructed and analysed using mixed effects linear regression to examine the predictive effect of smoking status on each outcome of interest with surgeon as a random variable.

\section{RESULTS}

One hundred and twenty-six patients met the inclusion criteria for the study, 18 smokers (14\%) and $108(86 \%)$ non-smokers. The presenting demographics of both smokers and non-smokers are displayed in table 1. At baseline, the smoking group had a greater proportion of females, more comorbidities and worse ASES and VAS Pain scores. There was a trend towards larger tear size and younger age in the smoking group that did not reach statistical significance.

The outcome scores for ASES, VAS pain and WORC are plotted longitudinally over time in figures $1-3$. ASES scores were lower at baseline and at almost every time point postoperatively in smokers (figure 1). VAS pain scores started higher in the smoking group, but there was no difference in VAS pain after 32 weeks postoperatively (figure 2).

While there was a tendency to have better WORC scores in the non-smoking group, the only time points that reached statistical significance were 16 weeks and 2 years (figure 3). Notably, all three ASES, VAS pain and WORC outcomes worsened in between the 1 year and 2 years timepoints in the smoking group, but this late decline was not present or present to a much lesser degree in the non-smoking group. 


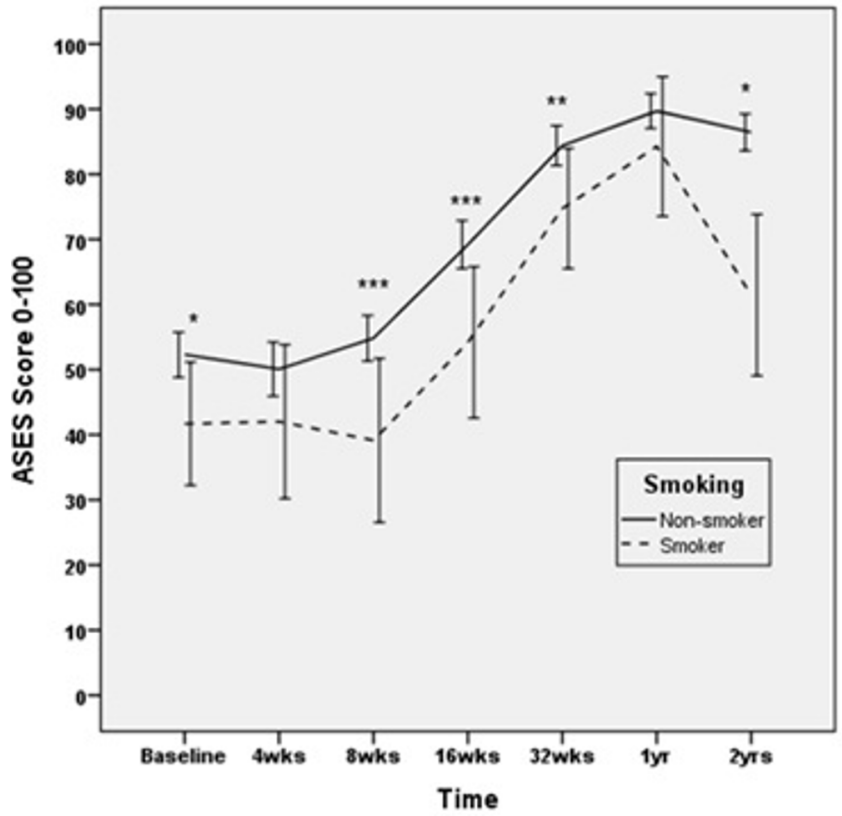

Figure 1 Mean ASES plotted over time for smokers and non-smokers. Error bars indicate 95\% Cls. Statistical significance is denoted by asterisks: ${ }^{*} \mathrm{p}<0.05$, ${ }^{\star *} \mathrm{p}<0.01$, ${ }^{* \star *} p<0.001$. ASES, American Shoulder and Elbow Score.

Table 2 reports the mean change in each outcome measure between baseline and final follow-up. In both smokers and non-smokers, there were statistically significant improvements in all three measures between baseline and final follow-up. When comparing the mean changes in scores between smokers and non-smokers, only ASES had a greater mean improvement from baseline scores in the non-smoking group. Regression analysis controlling

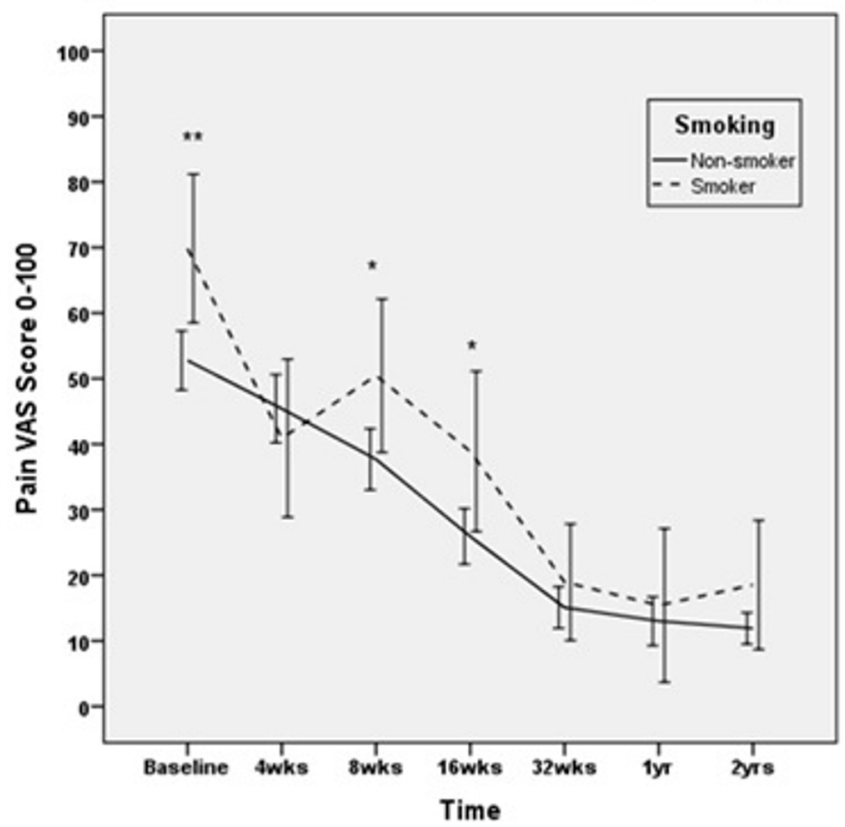

Figure 2 Mean VAS for pain plotted over time for smokers and non-smokers. Error bars indicate $95 \%$ Cls. Statistical significance is denoted by asterisks: ${ }^{*} \mathrm{p}<0.05$, ${ }^{\star *} \mathrm{p}<0.01$, ${ }^{\star * \star} p<0.001$. VAS, Visual Analogue Scale.

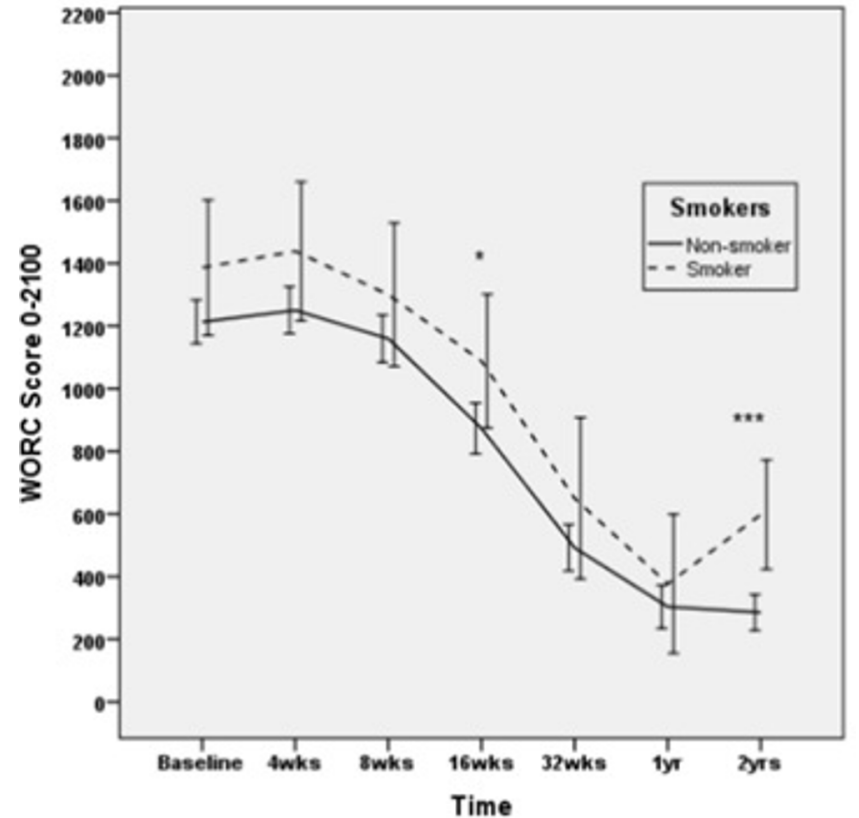

Figure 3 Mean WORC index plotted over time for smokers and non-smokers. Error bars indicate 95\% Cls. Statistical significance is denoted by asterisks: ${ }^{*} p<0.05,{ }^{* *} p<0.01$, ${ }^{\star \star *} \mathrm{p}<0.001$. WORC, Western Ontario Rotator Cuff.

for demographic factors, comorbidities and tear size confirmed that smoking resulted in worse improvement in ASES $(B=-0.18, p=0.04$, $\mathrm{CI}-22.7$ to 3.1$)$, but not in WORC $(\mathrm{B}=-0.02, \mathrm{p}=0.73$, $\mathrm{CI}-243$ to 173$)$ or VAS pain $(\mathrm{B}=0.04, \mathrm{p}=0.69$, $\mathrm{CI}-12.3$ to 18.7$)$ scores. Smoking quantity did not correlate with outcome scores.

\section{DISCUSSION}

In this cohort study, both smokers and non-smokers experienced improved outcomes after arthroscopic rotator cuff repair. Both groups achieved the minimal clinically important difference (MCID) at 2 years follow-up for ASES, WORC and VAS pain scores (12-17, 30 and 245, respectively). ${ }^{16-18}$ At baseline, smokers presented with worse comorbidities, pain and ASES scores. When controlling for comorbidities and demographics, smoking resulted in lower improvement in ASES but not WORC or VAS pain scores.

The impact of smoking on the pathogenesis of rotator cuff tears is not well-defined. The pathogenesis of rotator cuff tears is linked to a poor vascular region or 'critical zone' within the distal $15 \mathrm{~mm}$ of the tendon insertion. ${ }^{7}$ Cigarette smoke may further exacerbate this phenomenon by the vasoconstricting effect of nicotine and the decreased oxygen availability caused by carbon monoxide. Additionally, in a rat model, Ichinose et al delivered a constant concentration of nicotine via an implanted pump onto the supraspinatus tendon. Nicotine caused the supraspinatus tendon to become stiffer, which may biomechanically predispose the tendon to injury and tearing. 19 
Table 2 Patient-reported outcomes response to treatment

\begin{tabular}{|c|c|c|c|c|c|c|c|c|c|}
\hline \multirow[t]{2}{*}{ 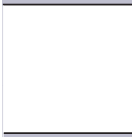 } & \multicolumn{4}{|l|}{ Smokers } & \multicolumn{4}{|c|}{ Non-smokers } & \multirow{2}{*}{$\begin{array}{l}\begin{array}{l}\text { Intergroup } \\
\text { comparison }\end{array} \\
\text { P values } \\
\end{array}$} \\
\hline & Baseline & 2 years & Change & $P$ values & Baseline & 2 years & Change & $P$ values & \\
\hline ASES & 42.1 & 61.5 & 19.4 & $<0.001^{*}$ & 52.3 & 87.5 & 35.2 & $<0.001^{*}$ & $0.005^{\star}$ \\
\hline VAS & 69.9 & 18.5 & 51.4 & $<0.001^{*}$ & 52.8 & 12.0 & 40.8 & $<0.001^{*}$ & 0.14 \\
\hline WORC & 1386 & 598 & 788 & $<0.001^{*}$ & 1213 & 297 & 916 & $<0.001^{*}$ & 0.27 \\
\hline
\end{tabular}

Intergroup comparison is the change in scores between the smoker and non-smoker groups.

*Indicates $p<0.05$.

ASES, American Shoulder and Elbow Score; VAS, Visual Analogue Pain Score; WORC, Western Ontario Rotator Cuff index.

Whether smoking is a risk factor for rotator cuff tears is controversial. Several authors have reported that smokers tend to present with larger rotator cuff tears at an earlier age than non-smokers, ${ }^{20-22}$ while others have found no association between smoking and rotator cuff tears. ${ }^{23}{ }^{24}$ In our cohort, smokers presented on average 5 years younger with cuff tears that were $1.9 \mathrm{~cm}^{2}$ larger in area compared with non-smokers. However, neither difference reached statistical significance with our sample size.

In addition to pathogenesis, smoking may impair the healing potential of the rotator cuff. Lundgreen et al took biopsies of torn supraspinatus tendons at the time of surgery and demonstrated that torn tendons from smokers have greater degenerative changes and cellular apoptosis compared with non-smokers. ${ }^{25}$ Furthermore, Galatz et al used a rat model of rotator cuff repair to show that nicotine prolonged rotator cuff tendon-to-bone healing and reduced the mechanical properties of the repair site. ${ }^{26}$

Despite this basic science evidence, mixed results have been published on whether smoking has a negative impact on arthroscopic rotator cuff repairs. ${ }^{11}{ }^{27-29}$ In our study, we noted a pronounced decrease in patient-reported outcomes after 1 year for smokers that was not present in non-smokers. Follow-up imaging was not available in the present study, so it is unclear if cuff tear integrity may have contributed to this decline in the smoking group.

Mallon et al first reported that smokers have worse UCLA scores at baseline and lower improvement in scores following open rotator cuff repair. ${ }^{10}$ Similarly, Balyk studied predominantly open rotator cuff repairs and found smoking was an independent predictor of lower ASES and WORC scores at 6 months. ${ }^{12}$ Meanwhile, Prassad observed no effect of smoking on Constant scores after open cuff repairs, but the study was likely underpowered with only 42 patients. For arthroscopic repairs, Nho reported that patients who were current or former smokers had no difference in healing rates or outcomes. ${ }^{28}$

Our study is one of the first reports of worse functional improvement as measured by ASES in active or recent smokers after arthroscopic rotator cuff repair. WORC scores also trended to a lower functional improvement in smokers in our study, but this did not reach statistical significance. Interestingly, smokers in our study had a non-significant trend towards a greater improvement in VAS pain, probably related to the fact that smokers presented with more baseline pain and the VAS pain measure may have had a floor effect.

A strength of our study is the rigorous data collection and follow-up of patients as part of our single institution cohort. We used an array of patient-reported outcome measures that were collected in a standardised fashion across 2 years, enabling us to compare smokers versus non-smokers at multiple time points. Additionally, a number of demographic factors, coexisting comorbidities, surgeon and tear size were controlled for by our study design.

An important limitation to recognise in our study is the low number of smokers in our study population. Only $14 \%$ of our study population were active or recent smokers. While this number is much lower than previous reports, our smoking prevalence is on par with the 2015 CDC estimate of $15.1 \%$ active smokers in the USA. ${ }^{30} \mathrm{~A}$ posthoc power analysis to detect MCID in ASES revealed that our sample size achieved a power of 0.7 . The large effect sizes in our study allowed us to demonstrate statistical differences in ASES, but our study may have still been underpowered to report differences in presentation CTI and WORC scores. Additionally, although we collected quantity of smoking, the number of smokers in our study did not permit a subgroup analysis. Finally, this was a retrospective review of a prospective cohort, and imaging was not available to determine whether smoking impacted cuff repair healing rates in addition to outcomes. Instead, we used patient-reported outcomes to determine response to rotator cuff repair.

\section{CONCLUSION}

Both smokers and non-smokers achieve the MCID in ASES, WORC and VAS pain scores at 2 years following arthroscopic rotator cuff repair. On initial presentation, smokers had worse comorbidities, pain and ASES scores. Smokers also had a non-significant trend towards presenting for surgery at a younger age with larger tears. When controlling for comorbidities, demographics and tear size, smoking resulted in lower improvement after rotator cuff repair for ASES, but not for WORC or VAS pain scores. Further research is needed to define the 
negative impact of smoking and determine the necessity of smoking cessation prior to rotator cuff surgery.

Contributors Each author had a substantial contribution to the study design, data acquisition, analysis and manuscript composition. All authors have read and approved the final manuscript.

Funding The authors have not declared a specific grant for this research from any funding agency in the public, commercial or not-for-profit sectors.

Competing interests None declared.

Patient consent Not required.

Ethics approval University of Michigan IRB, Study \#: HUM00024612.

Provenance and peer review Not commissioned; externally peer reviewed.

Data sharing statement The data presented in this study is part of a multiple surgeon rotator cuff database with ongoing prospective enrolment at University of Michigan.

Open access This is an Open access article distributed in accordance with the Creative Commons Attribution Non Commercial (CC BY-NC 4.0) license, which permits others to distribute, remix, adapt, build upon this work non-commercially, and license their derivative works on different terms, provided the original work is properly cited, appropriate credit is given, any changes made indicated, and the use is non-commercial. See: http://creativecommons.org/licenses/by-nc/4.0/.

\section{REFERENCES}

1. Patel RA, Wilson RF, Patel PA, et al. The effect of smoking on bone healing: a systematic review. Bone Joint Res 2013;2:102-11.

2. Lee JJ, Patel R, Biermann JS, et al. The musculoskeletal effects of cigarette smoking. J Bone Joint Surg Am 2013;95:850-9.

3. Kanneganti P, Harris JD, Brophy RH, et al. The effect of smoking on ligament and cartilage surgery in the knee: a systematic review. Am $J$ Sports Med 2012;40:2872-8.

4. Santiago-Torres J, Flanigan DC, Butler RB, et al. The effect of smoking on rotator cuff and glenoid labrum surgery: a systematic review. Am J Sports Med 2015;43:745-51.

5. Bishop JY, Santiago-Torres JE, Rimmke N, et al. Smoking predisposes to rotator cuff pathology and shoulder dysfunction: a systematic review. Arthroscopy 2015;31:1598-605.

6. Mosely LH, Finseth F. Cigarette smoking: impairment of digital blood flow and wound healing in the hand. Hand 1977;9:97-101.

7. Blevins FT, Djurasovic M, Flatow EL, et al. Biology of the rotator cuff tendon. Orthop Clin North Am 1997;28:1-16.

8. Leow YH, Maibach HI. Cigarette smoking, cutaneous vasculature, and tissue oxygen. Clin Dermatol 1998;16:579-84.

9. Pedowitz RA, Yamaguchi K, Ahmad CS, et al. Optimizing the management of rotator cuff problems. J Am Acad Orthop Surg 2011;19:368-79.

10. Mallon WJ, Misamore G, Snead DS, et al. The impact of preoperative smoking habits on the results of rotator cuff repair. J Shoulder Elbow Surg 2004;13:129-32.

11. Tashjian RZ, Hollins AM, Kim HM, et al. Factors affecting healing rates after arthroscopic double-row rotator cuff repair. Am J Sports Med 2010;38:2435-42.
12. Balyk R, Luciak-Corea C, Otto D, et al. Do outcomes differ after rotator cuff repair for patients receiving workers' compensation? Clin Orthop Relat Res 2008;466:3025-33.

13. Prasad N, Odumala A, Elias F, et al. Outcome of open rotator cuff repair. an analysis of risk factors. Acta Orthop Belg 2005;71:662-6.

14. Groll DL, To T, Bombardier C, et al. The development of a comorbidity index with physical function as the outcome. J Clin Epidemiol 2005;58:595-602.

15. Tauro JC. Stiffness and rotator cuff tears: incidence, arthroscopic findings, and treatment results. Arthroscopy 2006;22:581-6.

16. Tashjian RZ, Deloach J, Porucznik CA, et al. Minimal clinically important differences (MCID) and patient acceptable symptomatic state (PASS) for visual analog scales (VAS) measuring pain in patients treated for rotator cuff disease. J Shoulder Elbow Surg 2009:18:927-32.

17. Tashjian RZ, Deloach J, Green A, et al. Minimal clinically important differences in ASES and simple shoulder test scores after nonoperative treatment of rotator cuff disease. J Bone Joint Surg Am 2010;92:296-303.

18. Kirkley A, Griffin S, Dainty K. Scoring systems for the functional assessment of the shoulder. Arthroscopy 2003;19:1109-20.

19. Ichinose R, Sano H, Kishimoto KN, et al. Alteration of the material properties of the normal supraspinatus tendon by nicotine treatment in a rat model. Acta Orthop 2010;81:634-8.

20. Baumgarten KM, Gerlach D, Galatz LM, et al. Cigarette smoking increases the risk for rotator cuff tears. Clin Orthop Relat Res 2010;468:1534-41.

21. Carbone S, Gumina S, Arceri V, et al. The impact of preoperative smoking habit on rotator cuff tear: cigarette smoking influences rotator cuff tear sizes. J Shoulder Elbow Surg 2012;21:56-60.

22. Kukkonen J, Kauko T, Virolainen $P$, et al. Smoking and operative treatment of rotator cuff tear. Scand J Med Sci Sports 2014;24:400-3.

23. Titchener AG, White JJ, Hinchliffe SR, et al. Comorbidities in rotator cuff disease: a case-control study. $J$ Shoulder Elbow Surg 2014;23:1282-8.

24. Fehringer EV, Sun J, VanOeveren LS, et al. Full-thickness rotator cuff tear prevalence and correlation with function and co-morbidities in patients sixty-five years and older. J Shoulder Elbow Surg 2008; $17: 881-5$

25. Lundgreen $\mathrm{K}$, Lian OB, Scott $\mathrm{A}$, et al. Rotator cuff tear degeneration and cell apoptosis in smokers versus nonsmokers. Arthroscopy 2014;30:936-41.

26. Galatz LM, Silva MJ, Rothermich SY, et al. Nicotine delays tendonto-bone healing in a rat shoulder model. J Bone Joint Surg Am 2006;88:2027-34.

27. Kim IB, Kim MW. Risk factors for retear after arthroscopic repair of full-thickness rotator cuff tears using the suture bridge technique: classification system. Arthroscopy 2016;32:2191-200.

28. Nho SJ, Brown BS, Lyman S, et al. Prospective analysis of arthroscopic rotator cuff repair: prognostic factors affecting clinical and ultrasound outcome. J Shoulder Elbow Surg 2009:18:13-20.

29. Neyton L, Godenèche A, Nové-Josserand L, et al. Arthroscopic suture-bridge repair for small to medium size supraspinatus tear: healing rate and retear pattern. Arthroscopy 2013;29:10-17.

30. Center for Disease Control and Prevention (CDC). Cigarette smoking among adults - United States, 2005-2015. Morbidity and Mortality Weekly Report 2016;65:1205-11. 